\title{
Trefoil Peptides Promote Epithelial Migration through a Transforming Growth Factor $\beta$-independent Pathway
}

Axel Dignass, * Kathryn Lynch-Devaney, * Heather Kindon, * Lars Thim, ${ }^{\ddagger}$ and Daniel K. Podolsky *

*Gastrointestinal Unit, Massachusetts General Hospital and MGH/NERPRC Center for the Study of Inflammatory Bowel Disease, Boston, Massachusetts 02114; and ${ }^{\ddagger}$ Novo Research Institute, Copenhagen, Denmark DK2880

\begin{abstract}
The trefoil peptides, a recently recognized family of protease-resistant peptides, expressed in a regional specific pattern throughout the normal gastrointestinal tract. Although these peptides have been hypothesized to act as growth factors, their functional properties are largely unknown. Addition of recombinant trefoil peptides human spasmolytic polypeptide (HSP), rat and human intestinal trefoil factor (RITF and HITF) to subconfluent nontransformed rat intestinal epithelial cell lines (IEC-6 and IEC-17), human colon cancer-derived cell lines (HT-29 and CaCO2) or nontransformed fibroblasts (NRK and BHK) had no significant effect on proliferation. However addition of the trefoil peptides to wounded monolayers of confluent IEC-6 cells in an in vitro model of epithelial restitution resulted in a 3-6-fold increase in the rate of epithelial migration into the wound. Stimulation of restitution by the trefoil peptide HSP was enhanced in a cooperative fashion by the addition of mucin glycoproteins purified from the colon or small intestine of either rat or man, achieving up to a 15 -fold enhancement in restitution. No synergistic effect was observed by the addition of nonmucin glycoproteins. In contrast to cytokine stimulation of intestinal epithelial cell restitution which is mediated through enhanced TGF $\beta$ bioactivity, trefoil peptide, and trefoil peptide-mucin glycoprotein stimulation of restitution was not associated with alteration in concentrations of bioactive TGF- $\beta$ and was not affected by the presence of immunoneutralizing anti-TGF $\beta$ antiserum. Collectively, these findings suggest that the trefoil peptides which are secreted onto the lumenal surface of the gastrointestinal tract may act in conjunction with the mucin glycoprotein products of goblet cells to promote reestablishment of mucosal integrity after injury through mechanisms distinct from those which may act at the basolateral pole of the epithelium. (J. Clin. Invest. 1994. 94:376-383.) Key words: mucosal injury $\bullet$ growth $\cdot$ goblet cells $\bullet$ healing
\end{abstract}

\section{Introduction}

Over the past several years a family of small peptides expressed at various sites throughout the gastrointestinal tract and desig-

Address all correspondence to D. K. Podolsky, Gastrointestinal Unit, Massachusetts General Hospital, Fruit Street, Boston, MA 02114.

Received for publication 12 November 1993 and in revised form 3 February 1994.

J. Clin. Invest.

(c) The American Society for Clinical Investigation, Inc.

0021-9738/94/07/0376/08 \$2.00

Volume 94 , July $1994,376-383$ nated trefoil factors have been identified through a range of approaches. The members of this family share an array of structural features including, most notably, a motif of six cysteine residues termed a trefoil or a $\mathbf{P}$ domain, which is distinct from those found in other peptide families. Noting the shared cysteine motif present in the first two members of this family to be identified, Thim (1) postulated that the six cysteine residues could contribute to the formation of three intrachain loops via the formation of disulfide bonds; the resultant predicted three looped structure prompted the trefoil (three leaf) designation. A recent nuclear magnetic resonance (NMR) analysis of one of the trefoil peptides supported the presence of a distinctive secondary structure consistent with the putative three intrachain loop formation (2). Various members of the family identified in mammals include one or two $\mathbf{P}$ domains (3-5). Amphibians have been found to express trefoil proteins with one to as many as four $\mathrm{P}$ domains (6).

Members of the trefoil peptide family appear to be expressed in a regional specific fashion throughout the gastrointestinal tract in a manner which has been conserved through evolution. Thus pS2, a peptide which was first identified through its ectopic expression in many hormonally responsive breast carcinomas is normally expressed predominantly in gastric mucosa $(7,8)$. The trefoil peptides containing two $\mathrm{P}$ domains (e.g., human and porcine spasmolytic polypeptides [HSP and PSP] $)^{1}$ are found in the distal stomach and pancreas while intestinal trefoil factor (ITF) containing one $P$ domain, is found in small and large intestinal mucosa from the duodenum to the rectum $(4,5,9$, 10). The trefoil peptide family appears to be relatively ancient with homologues present in the amphibian stomach and skin (designated XSL) $(6,11-14)$. However regional specific factors appear to have been individually conserved; the overall homologies among trefoil peptides found at different sites in the gastrointestinal tract within a single species range from 35 to $45 \%$ (e.g., human ITF vs. human pS2 $=37 \%$ homology), while the corresponding trefoil factors from different species may be as much as $85 \%$ identical (e.g., human vs. rat ITF $=82 \%$ identity) (9).

Although the high degree of evolutionary conservation of trefoil peptides and their abundance suggest that these peptides subserve important functions, insights into their physiological actions have been limited (11). Interestingly, increased expression of trefoil peptides has been observed in association with ulceration in the gastrointestinal tract and has been localized to a cell thought to contain growth regulatory peptides (15-17). It has been suggested that they may serve as growth factors and one member has been reported to modestly stimulate prolifera-

1. Abbreviations used in this paper: HSP and PSP, human and porcine spasmolytic polypeptide; RCGP and HCGP, rat and human colonic mucin glycoproteins; RITF and HITF, rat and human intestinal trefoil factor. 
tion of colon cancer-derived cell lines (18). However, the abundance of these peptides in the mucosa contrasts with the relatively low concentrations of previously described "conventional" peptide growth factors which modulate proliferation through interaction with high affinity specific cell surface receptors. Early studies suggested that at least one member of the family, porcine spasmolytic polypeptide (PSP), could alter both gastric acid secretion and gastrointestinal tract motility but whether these reflect direct physiological functions remains unclear (19-21).

Although it is possible that the trefoil peptides serve a systemic function, it is notable that these peptides appear to be produced by goblet cells in the small and large intestine and their counterparts in other areas of the gastrointestinal tract, which secrete them onto the lumenal mucosal surface, presumably in conjunction with mucin glycoproteins $(9,10)$. It is therefore possible that these peptides exert their most important function at the lumenal-mucosal interface where they are most abundant, possibly contributing in some fashion to the integrity of mucosal surface continuity. Indeed, these peptides may be structurally well suited to survive in a functional state despite the inevitable exposure to the lumenal proteases present throughout the gastrointestinal tract. Jorgenson et al. (21) have directly demonstrated a high degree of resistance to protease digestion of PSP which they ascribed to a compact structure of the PSP molecule. Comparable protease resistance has also been observed for ITF (H. Kindon and D. K. Podolsky, manuscript in preparation). In the present study, we explore the effects of model trefoil peptides alone and in conjunction with mucin glycoproteins on the restitution of wounded intestinal epithelial monolayers. Although the trefoil peptides did not appear to alter proliferation of these cell lines, they acted in a synergistic fashion to enhance the rate of restitution through a pathway distinct from that utilized by cytokines present at the basolateral surface.

\section{Methods}

Materials. Recombinant HSP (rHSP) was produced in yeast and purified as previously described (22). In the present study the nonglycosylated form of rHSP was used, though essentially equivalent results were observed with glycosylated rHSP. Recombinant rat and human ITF (RITF and HITF) were produced after cloning the corresponding full length cDNAs into a commercially available baculovirus vector (Maxbac; Invitrogen, Sunnydale, CA) and expressed in the Sf9 insect cell line (H. Kindon and D. K. Podolsky, manuscript in preparation); equivalence with the native protein was confirmed by Western blot and SDSPAGE analysis using a previously characterized anti-ITF specific antisera (10).

Mucin glycoproteins were purified from human colonic mucosa as previously reported $(23,24)$; mucin glycoproteins were purified and used without further chromatographic fractionation into individual species. Nonmucin glycoproteins from human and rat colonic mucosa were separated on Sepharose 4B from the mucin glycoproteins obtained for comparative studies by chromatography performed as previously reported $(23,24)$. The nonmucin glycoproteins recovered in the included volume were exhaustively dialyzed against water and lyophilyzed. Mucin glycoproteins were also purified from colonic mucosa and small intestinal mucosa from Sprague-Dawley rats essentially by application of the same techniques as used by others (25). In all instances, mucin glycoproteins were recovered after $\mathrm{CsCl}$ density centrifugation with a buoyant density of $>1.45 \mathrm{~g} / \mathrm{ml}$.

Porcine TGF $\beta_{1}(26,27)$ was obtained from R\&D systems (Minneapolis, MN), turkey anti-human TGF $\beta_{1}$ antiserum from Collaborative
Research (Bedford, MA). Previous studies in this laboratory have demonstrated that $50 \mu \mathrm{l}$ of this antisera can immunoneutralize up to $100 \mathrm{ng}$ of either human or rat TGF $\beta_{1}$ (see references 29 and 39). Bovine serum albumin (BSA) was obtained from Sigma Chemical Co. (St. Louis, MO). IEC-6, a nontransformed intestinal epithelial cell line established in this laboratory from neonatal rat intestine was used in 16th-19th passage (28). Mv1Lu cells, a TGF $\beta_{1}$ sensitive line was obtained from the ATCC (48th-50th passage).

Restitution (migration) in an in vitro model of wounding. Wound assays were performed as previously described $(29,30)$ using a modification of the method developed by Sato and Rifkin (31). Confluent monolayers of IEC-6 cells in 24-well multiwell plates were wounded with a razor blade sized to yield a $4-5-\mathrm{mm} \times 1 \mathrm{~cm}$ wound in each well. Cells were washed with fresh serum-deprived medium to remove any residual cell debris and the wounded monolayers were subsequently cultured for a further $24 \mathrm{~h}$ in fresh serum-deprived medium in the presence or absence of various proteins or glycoproteins in a range of concentrations individually or in combination: rHSP, RITF, HITF, HCGP, RCGP, HCNMGP, RCNMGP, BSA, TGF $\beta_{1}$, or anti-TGF $\beta_{1}$ antiserum.

Migration of IEC- 6 cells was assessed by blinded counting of the number of IEC- 6 cells observed across the wound border expressed as the mean number of cells present across the wound border in a standardized length $(2 \mathrm{~mm})$ using photomicrographs taken at $100 \times$ with an inverted microscope Nikon Diaphor TMS and a Nikon N6006 camera. Duplicate wells were used in each experiment and three wound areas per well were used to quantitate migration; data from a minimum of three separate experiments were used for the determination of the effects of various substances on restitution (interassay variation $<10 \%$ ). Data are expressed as mean cell number across the standard wound edge unit \pm SD.

Determination of latent and bioactive TGF $\beta$. Latent and bioactive TGF $\beta$ were determined by a bioassay measuring inhibition of proliferation (incorporation of radiolabeled thymidine) by subconfluent mink lung epithelial cells (Mv1Lu) as described elsewhere (32). Briefly, for the determination of total (latent and bioactive) $\operatorname{TGF} \beta$, samples were first activated by acidification with $0.15 \mathrm{~N} \mathrm{HCl}$ for $60 \mathrm{~min}$, followed by neutralization before assay for TGF- $\beta$ bioactivity. Bioactive TGF $\beta$ was determined using samples without prior acidification. MvlLu cells $\left(1 \times 10^{5}\right.$ cells/well in 24-well plates) were seeded in $0.2 \%$ FCS in DME; $5 \mathrm{~h}$ after seeding, test samples or varying concentrations of the standard porcine platelet TGF $\beta_{1}$ were added and cells cultured for 24 $\mathrm{h}$ at $37^{\circ} \mathrm{C} .\left[{ }^{3} \mathrm{H}\right]$ thymidine $(1.5 \mu \mathrm{Ci} /$ well $)$ was added and the incubation was continued for an additional $4 \mathrm{~h}$. Cells were then washed with PBS and fixed in methanol:acetic acid (3:1 vol/vol). Acid insoluble material including thymidine incorporated into DNA was solubilized by addition of $1 \mathrm{~N} \mathrm{NaOH}$ and incorporated radioactivity determined in a liquid scintillation counter.

Effects of trefoil factors on cell proliferation. Cells (IEC-6, IEC17, HT-29, CaCO2, T84, LS180, NRK, BHK and AGS, [33], all obtained from the ATCC) were seeded into 24-well plate $\left(1-5 \times 10^{4}\right.$ cells/well) in the presence of DME containing 5\% FCS. When $\sim 50 \%$ confluent, cells were washed three times and then further cultured for $24 \mathrm{~h}$ in DME containing $0.1 \%$ FCS. Cultures were then supplemented with rHSP, RITF, HITF, HCGP, RCGP, RSIGP, or RGGP individually or in combination in concentrations ranging from $0.1-5 \mu \mathrm{g} / \mu \mathrm{l}$ as cited in the text. After $20 \mathrm{~h}$ at $37^{\circ} \mathrm{C},\left[{ }^{3} \mathrm{H}\right]$ thymidine $(1.8 \mu \mathrm{Ci} /$ well; $1 \mu \mathrm{Ci} /$ $\mu \mathrm{l})$ was added and after $4 \mathrm{~h}$, incorporation of radiolabeled thymidine determined as described above.

\section{Results}

Although the existence of a distinctive family of molecules designated trefoil peptides which in mammals are normally expressed almost exclusively in gastrointestinal mucosa and pancreas has been recognized, the physiological role $(s)$ of these abundant constituents which appear to be differentially secreted 
onto the mucosal surface have remained unclear. Some investigators have speculated that trefoil peptides may act fundamentally as growth factors, stimulating proliferation through interaction with cell surface receptors $(18,34,35)$. To test this hypothesis, the purified human trefoil peptide normally expressed in the proximal gastrointestinal tract HSP or semi-purified forms of the predominant trefoil peptide present in the small and large intestine ITF (rat and human) were added to subconfluent cultures of nontransformed rat intestinal epithelial cells (IEC-6 and IEC-17), human colon cancer-derived cell lines including those which retain the capacity to undergo phenotypic differentiation ( $\mathrm{CaCO} 2$ and HT-29) (33), a human gastric cancer-derived cell line (AGS) and a rodent nontransformed fibroblast line (NRK). As shown in Table I, none of the trefoil peptides had a significant effect on the proliferation of any of these cell lines within the 24-h time frame assessed by incorporation of thymidine into acid precipitable material; previous studies in this laboratory have confirmed that the latter correlates directly with proliferation in the intestinal, colon cancer-derived and fibroblast lines. Trefoil peptides were evaluated over a range of concentrations from $0.1-1 \mu \mathrm{g} / \mu \mathrm{l}$ without significant stimulation or inhibition of proliferation; incorporation of thymidine remained within $22 \%$ of the untreated controls in all studies. In contrast, the intestinal derived cell lines IEC- 6 and IEC- 17 were highly sensitive to the growth inhibiting effect of TGF $\beta_{1}$ ( $>90 \%$ inhibition at $5 \mathrm{pM}$ ) and the growth stimulatory effects of TGF $\alpha$ ( $>100 \%$ stimulation at $0.1 \mu \mathrm{g} / \mathrm{ml}$ ) used as comparative controls consistent with earlier observations in this laboratory and elsewhere (36). The effect of the trefoil peptides on proliferation of the cell lines in the copresence of human or rat colonic mucin glycoproteins was also determined insofar as circumstantial observations suggest that these may be co-secreted onto the mucosal surface in vivo. However, the addition of these large molecular weight glycoproteins did not result in emergence of previously latent effects on proliferation by the trefoil peptides (data not shown).

Although the trefoil peptides had no significant effect on growth in a variety of cell lines derived from gastrointestinal tract epithelium, we speculated that these proteins secreted in abundance onto the mucosal surface might promote epithelial integrity in a manner distinct from typical peptide growth factors. Subsequently, we evaluated the effect of these peptides on restitution in an in vitro model of mucosal (epithelial) injury. A contact-inhibited confluent monolayer of IEC-6 cells was wounded in a standard fashion with a razor blade and migration into the defect to reconstitute the continuity of the monolayer was monitored. Previous studies have demonstrated that several cytokines and "classical" growth factors which may be present at the basolateral side of the epithelial surface monolayer in vivo enhance the rate of restitution in this model $(29,37-39)$. To determine whether trefoil peptides which are present at the apical surface in vivo might have a complementary role in promoting the reestablishment of epithelial integrity, the trefoil peptides alone or in combination with mucin glycoproteins were added to wounded IEC- 6 cell monolayers.

As demonstrated in Figs. 1 and 2, HSP enhanced the migration of IEC- 6 cells into the wound approximately fourfold. No similar enhancement was seen when HSP was replaced with a nonspecific protein (BSA). Interestingly, the purified human mucin glycoprotein (HCGP) also enhanced restitution though to a lesser extent. However, the combined presence of HSP and HCGP led to a significant increase in the rate of restitution
Table I. Effect of Trefoil Peptides on Proliferation In Vitro

\begin{tabular}{|c|c|c|c|}
\hline Cell line & Trefoil peptide* & Incorporation of $\left[{ }^{3} \mathrm{H}\right]$ thymidine ${ }^{*}$ & Percentage control \\
\hline & & cpm $\pm S D / 10^{5}$ cells & \\
\hline \multirow[t]{4}{*}{ IEC-6 } & None & $1280 \pm 90$ & \\
\hline & HSP & $1410 \pm 230$ & 110.2 \\
\hline & RITF & $1520 \pm 280$ & 118.8 \\
\hline & HITF & $1440 \pm 210$ & 112.5 \\
\hline \multirow[t]{4}{*}{ IEC-17 } & None & $960 \pm 110$ & \\
\hline & HSP & $1230 \pm 140$ & 128.1 \\
\hline & RITF & $1070 \pm 160$ & 111.4 \\
\hline & HITF & $1150 \pm 180$ & 119.8 \\
\hline \multirow[t]{4}{*}{ HT-29 } & None & $2580 \pm 350$ & \\
\hline & HSP & $2930 \pm 420$ & 113.6 \\
\hline & RITF & $3850 \pm 740$ & 149.2 \\
\hline & HITF & $2360 \pm 390$ & 91.5 \\
\hline \multirow[t]{4}{*}{$\mathrm{CaCO} 2$} & None & $1020 \pm 100$ & \\
\hline & HSP & $1210 \pm 130$ & 118.6 \\
\hline & RITF & $1100 \pm 160$ & 107.8 \\
\hline & HITF & $530 \pm 70$ & 52.0 \\
\hline \multirow[t]{4}{*}{ T84 } & None & $11280 \pm 140$ & \\
\hline & HSP & $14500 \pm 1380$ & 128.5 \\
\hline & RITF & $9890 \pm 1250$ & 87.7 \\
\hline & HITF & $9540 \pm 930$ & 85.0 \\
\hline \multirow[t]{4}{*}{ AGS } & None & $250 \pm 40$ & \\
\hline & HSP & $180 \pm 30$ & 72.0 \\
\hline & RITF & ND & \\
\hline & HITF & ND & \\
\hline \multirow[t]{4}{*}{ NRK } & None & $15520 \pm 1690$ & \\
\hline & HSP & $17890 \pm 2170$ & 115.3 \\
\hline & RITF & $13090 \pm 2410$ & 84.3 \\
\hline & HITF & $18140 \pm 2760$ & 116.9 \\
\hline
\end{tabular}

* Purified recombinant HSP was added to DME at a concentration of $100 \mu \mathrm{g} / \mathrm{ml}$. RITF and HITF were added as supernatant from Sf9 transfected with baculovirus vector containing full length cDNAs encoding these peptides. Control cultures for comparative assays were supplemented with an equal volume (50 $\mu 1 / 500 \mu \mathrm{l}$ total culture volume) from supernatant of nontransfected Sf9 cells. $\quad{ }^{\ddagger}\left[{ }^{3} \mathrm{H}\right]$ thymidine was added 20 $\mathrm{h}$ after addition of factor to subconfluent cells. After further incubation for $4 \mathrm{~h}$, incorporation of radiolabel into acid precipitable material was determined as detailed in Methods. ND, not determined.

achieving a rate 6-15-fold higher than that observed in controls. The effect of the mucin glycoproteins was specific insofar as no comparable alteration in the rate of restitution was seen when nonmucin glycoproteins isolated from human colon were substituted either alone or in combination with HSP.

As demonstrated in Fig. 3, the ability of the human colonic mucin glycoproteins to act in a cooperative fashion with HSP appeared to be common to gastrointestinal tract mucin glycoproteins generally. Thus, rat colonic mucin glycoproteins alone and in combination with the trefoil peptide enhanced cell migration in this wounding model to a similar extent as that observed with the human colonic mucin glycoproteins. Furthermore, mucin glycoproteins isolated from another site of the rat gastrointesti- 

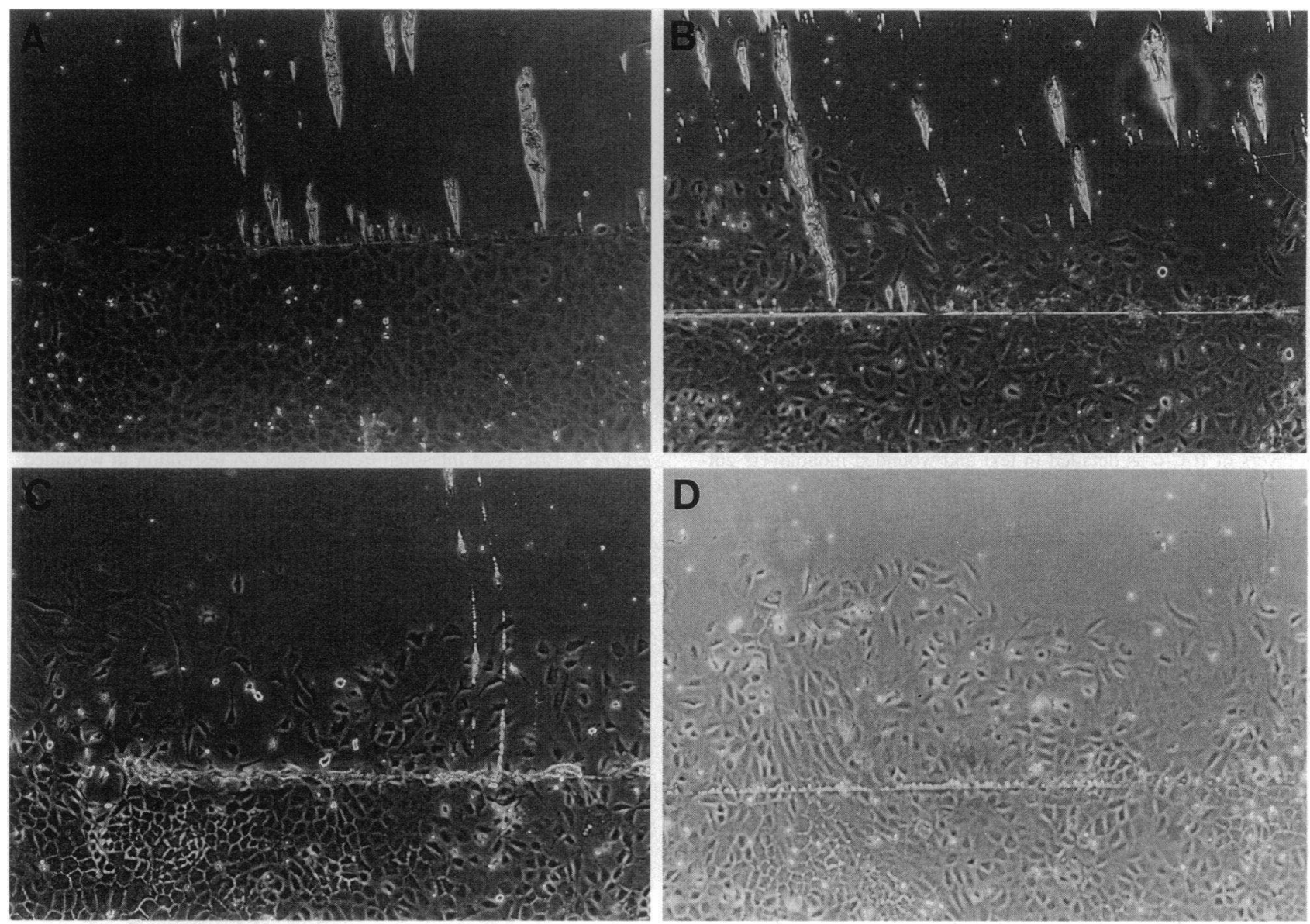

Figure 1. Cell migration in an in vitro model of restitution. Standard wounds were made with a razor blade in confluent monolayers of IEC-6 cells as previously described. After washing with fresh medium, wounded monolayers were cultured for $24 \mathrm{~h}$ in control media $(A)$ or media supplemented with the trefoil peptide HSP, $1 \mu \mathrm{g} / \mu \mathrm{l}(B)$, purified human colonic mucin glycoproteins, $1 \mu \mathrm{g} / \mu \mathrm{l}(C)$, or HSP and HCGP in combination $(D)$. Cells were fixed and photomicrographs taken $(\times 100)$. Scratch indicates original margin of wound.

nal tract (small intestine) also stimulated restitution in this model in combination with HSP. These data suggest that the mucin glycoproteins may interact functionally with HSP as a reflection of structural features common to these glycoconjugates as a class. Subsequent experiments suggested that these observations may also reflect properties common to the family of trefoil peptides. Partially purified rat and human ITF, the trefoil peptide normally expressed in the small and large intestine, also stimulated restitution of wounded IEC-6 and IEC-17 monolayers. Promotion of migration by the two species of ITF was further enhanced by the copresence of colonic mucin glycoproteins (Fig. 4). Collectively, these observations suggest that the ability to promote restitution, at least in this simplified in vitro model, is a property characteristic of the mammalian trefoil peptides as a family which may be enhanced through interaction with secreted mucin glycoproteins generally.

The relationship between rate of restitution in this in vitro model and the relative and absolute concentrations of trefoil peptides and mucin glycoproteins was explored through the assessment of migration following addition of varying amounts of HSP and HCGP. The limited quantities of ITFs precluded extending these studies to encompass these factors at this time. As demonstrated in Fig. 5, the rate of restitution was proportional to both the absolute and relative concentrations of HSP and HCGP. A dose-response relationship was seen when either HSP or HCGP were added alone in increasing concentrations: maximal levels of migration for HSP and HCGP were observed at concentrations of $2.5 \mu \mathrm{g} / \mu \mathrm{l}$ for both proteins. It should be noted that previous estimates suggest that each of these constituents may be physiologically present in essentially equal or greater concentrations at the mucosal surface. Cooperative stimulation of restitution was seen at lower concentrations of the individual substances when added together; enhancement observed in the presence of the "optimal" concentrations was greater than that observed at maximal effective concentrations of either individual component.

As noted above, previous studies in this laboratory and elsewhere have demonstrated that a number of cytokines and peptide growth factors (IL1, IL-2, IFN ${ }_{\gamma}$, TGF $\alpha / E G F$, and TGF $\beta$ ) also promote enhanced restitution in this in vitro model (29, $37-40$ ). The studies in this laboratory also demonstrated that all of these peptides acted through a TGF $\beta$-dependent pathway: stimulation of restitution could be entirely abrogated by the addition of neutralizing anti-TGF $\beta$ antiserum. Further, all of these factors stimulated endogenous production of bioactive TGF $\beta$ by the wounded monolayer and enhanced restitution by these exogenous peptides (except TGF $\beta$ itself) could also be blocked by addition of protease inhibitors (e.g., aprotinin or 


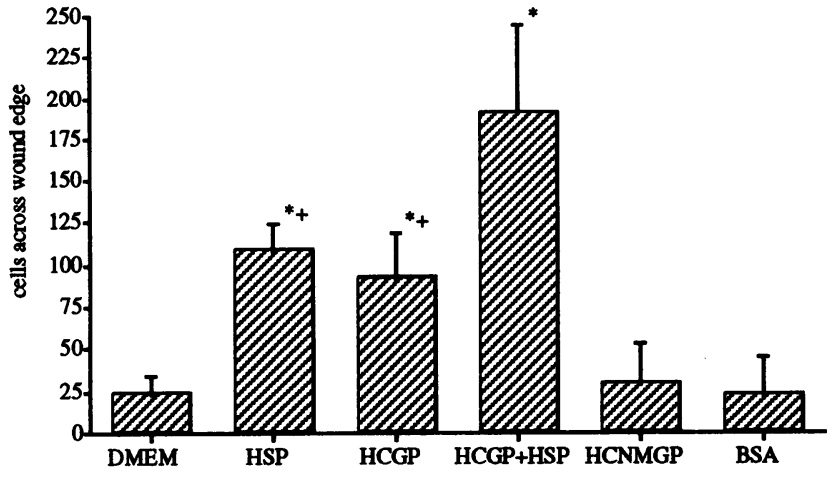

Figure 2. Effect of HSP and mucin glycoproteins on restitution in wounded IEC-6 monolayers. Wounds were established in confluent monolayers of IEC- 6 as detailed in text and wounded monolayers cultured for $24 \mathrm{~h}$ after addition of control media or media containing HSP and/or HCGP (former $1.0 \mu \mathrm{g} / \mu \mathrm{l}$, the latter $1.0 \mu \mathrm{g} / \mu \mathrm{l}$ ). Nonmucin glycoproteins $(1.0 \mu \mathrm{g} / \mu \mathrm{l})$ isolated in parallel from human colonic mucosa were also assessed and the nonspecific protein BSA $(1 \mu \mathrm{g} / \mu \mathrm{l})$ were also evaluated. Cells migrating across the wound margin as depicted in Fig. 1, were quantitated by blinded determination of the number of cells/standard distance obtained in quadruplicate from each of two wells in at least three separate experiments. Results presented as mean \pm SD. ${ }^{*} P<0.001$ compared with $\mathrm{DME} ;{ }^{+} P<0.01$ compared with HCGP + HSP.

epsilon amino caproic acid) which prevent the bioactivation of TGF $\beta$ from its precursor state (41). To determine whether the trefoil factors and/or the mucin glycoproteins also stimulate restitution through the same or a comparable TGF $\beta$-dependent pathway, migration after addition of these substances was assessed in the presence of an excess of the same immunoneutralizing anti-TGF $\beta$ antiserum. In contrast to the previously studied

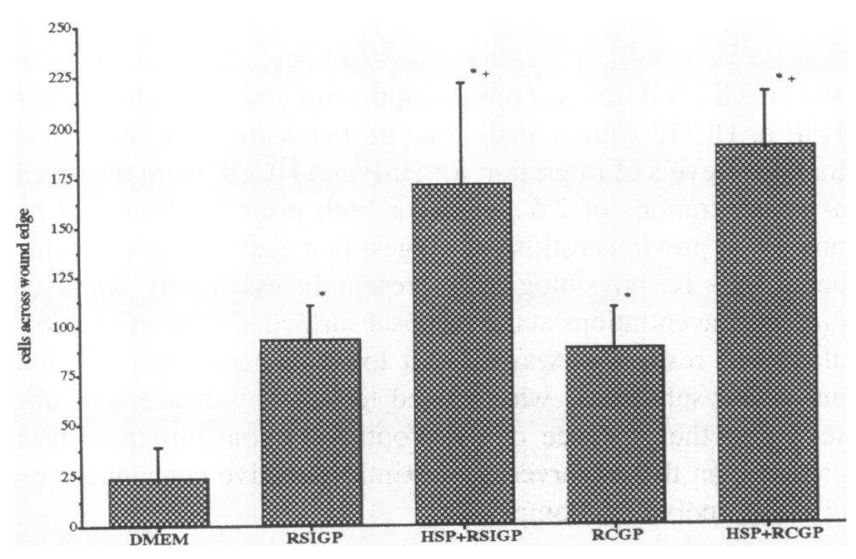

Figure 3. Effects of gastrointestinal tract mucin glycoproteins on restitution in wounded IEC-6 monolayers. Wounds were established in confluent monolayers of IEC- 6 as detailed in text and wounded monolayers cultured for $24 \mathrm{~h}$ after addition of control media or media containing mucin glycoproteins $(1 \mu \mathrm{g} / \mu \mathrm{l})$ isolated from rat small intestine or colon (designated RSIGP and RCGP, respectively) or in combination with HSP $(1 \mu \mathrm{g} / \mu \mathrm{l})$. Cells migrating across the wound margin as depicted in Fig. 1, were quantitated by blinded determination of the number of cells/standard distance obtained in quadruplicate from each of two wells in at least three separate experiments. Results presented as mean \pm SD. ${ }^{*} P<0.001$ compared with control; ${ }^{+} P<0.004$ compared with respective glycoprotein alone.

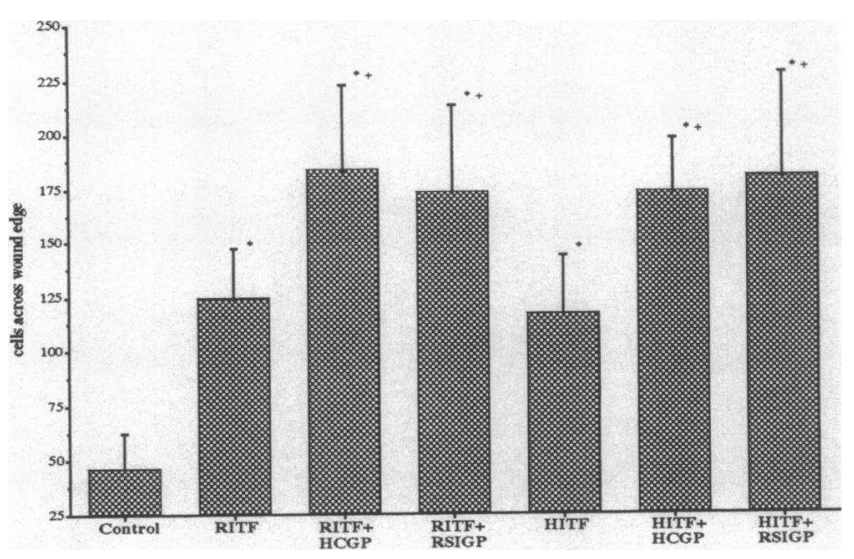

Figure 4. Effects of intestinal trefoil factor on restitution in wounded IEC-6 monolayers. Recombinant rat and human ITF (RITF and HITF) were produced by molecular cloning of full length cDNAs encoding these peptides into a baculovirus expression system and crude factor obtained in the media from transfected Sf 9 cells. Wounds were established in confluent monolayers of IEC- 6 as detailed in text and wounded monolayers cultured for $24 \mathrm{~h}$ after addition of control media or media containing RITF or HITF ( $10 \% \mathrm{vol} / \mathrm{vol} \mathrm{CM}$ in serum deprived DME; estimated concentration $1 \mu \mathrm{g} / \mu \mathrm{l})$ alone or in the presence of either RSIGP or HCGP $(2 \mu \mathrm{g} / \mu \mathrm{l})$. Cells migrating across the wound margin as depicted in Fig. 1, were quantitated by blinded determination of the number of cells/standard distance obtained in duplicate from each of two wells in at least three separate experiments. Results presented as mean $+/-$ SD. $* P<0.001$ compared with control; ${ }^{+} P<0.004$ compared with RITF/HITF alone.

cytokines, anti-TGF $\beta$ had no effect on the stimulation of restitution by HSP, HCGP, or the combination of HSP and HCGP (Fig. 6). Subsequently, the effects of the trefoil peptides and mucin glycoprotein on production of TGF $\beta$ peptide by the wounded monolayer were also assessed. As demonstrated in Fig. 7 , in contrast to the previously studied cytokines, neither HSP nor HCGP alone or in combination significantly altered the production of TGF $\beta$ by the wounded monolayer. Addition of TGF $\beta$ ( $1 \mathrm{pM})$ itself in the presence of HSP and HCGP function increased migration $28 \% \pm 6 \%$ (not pictured). Collectively, these findings indicate that the trefoil peptides do not promote restitution through a TGF $\beta$-dependent pathway.

\section{Discussion}

The mucosal surface of the gastrointestinal tract forms an extended interface with the environment. Although the full complexity of the various host defenses present in the lamina propria has not been delineated, it is evident that the physical continuity of the surface epithelium and its barrier function are essential. In the normal mucosa, tight junctions between epithelial cells are especially important, preventing penetration of large molecular weight materials through paracellular pathways $(42,43)$. In addition, a continuous viscoelastic coat overlying the lumenal (apical) surface has also been appreciated, though its functional importance in preserving or reestablishing mucosal continuity has been largely presumptive. This coat has been thought to consist largely, if not entirely of hydrated mucin glycoproteins secreted by the large population of goblet cells or their counterparts in the proximal gastrointestinal tract which are inter- 


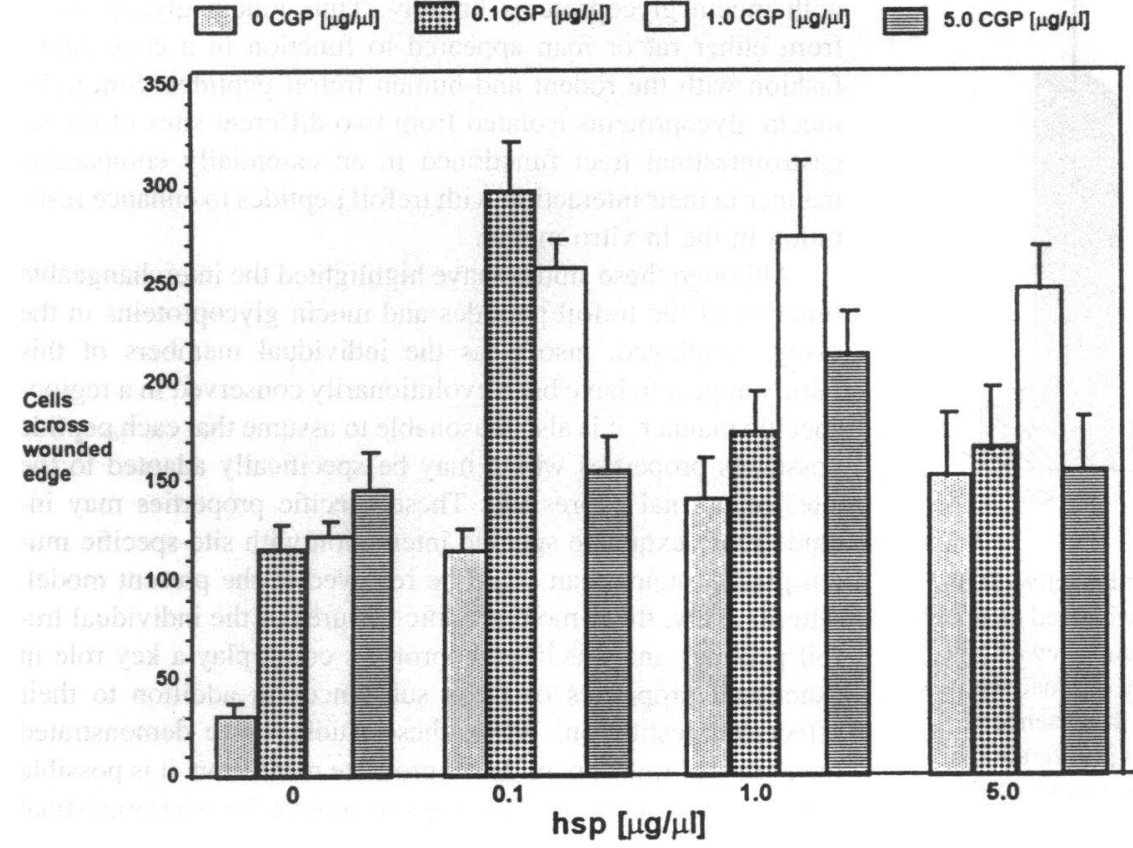

Figure 5. Effects of varying concentrations of HSP and HCGP on restitution in wounded IEC6 monolayers. The effects of HSP and HCGP on cellular restitution were assessed as described in text and legend to Fig. 2, using various concentrations of each of these factors alone or in combination as indicated in the figure. spersed among the other epithelial cell populations that collectively form the mucosal surface.

In addition to the structural continuity of the normal surface epithelium, mechanisms to reestablish this integrity after the many forms of injury that affect the gastrointestinal mucosa are essential. Although replacement of cells lost after mucosal ulceration through proliferation is ultimately necessary, this process requires an extended period of time. A number of investigators have demonstrated that the continuity of the epithelial surface population is more rapidly established by the process of restitution in which cells at the margins of areas of mucosal injury extend themselves and migrate over a period of hours (44-48). This process which has been observed after a variety of forms of mucosal injury in both the upper and lower gastrointestinal tract is remarkable for the rapidity through which even

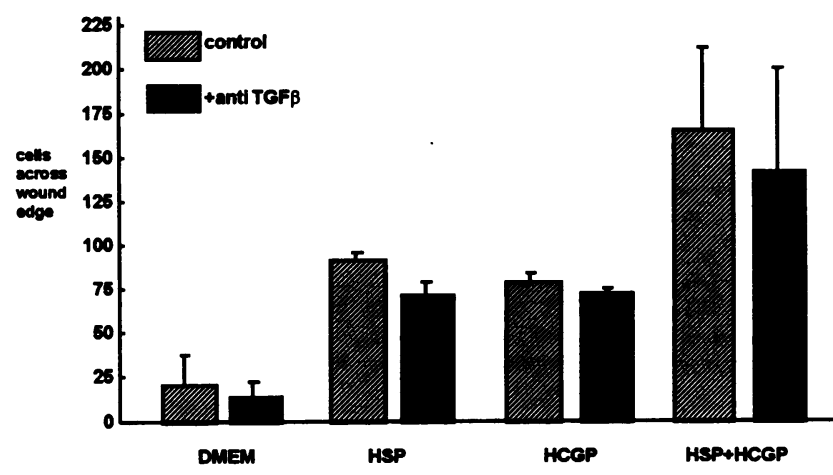

Figure 6. Role of TGF $\beta$ in HSP and mucin glycoprotein stimulation of intestinal epithelial restitution. HSP and/or HCGP were added to wounded IEC-6 monolayers as described in legend to Fig. 2 in the presence of an immunoneutralizing anti-TGF $\beta$ antiserum or nonspecific serum and cellular migration quantitated as described. Confirmation of immunoneutralizing ability of anti-serum was confirmed by ability to inhibit migration stimulation by exogenous rodent $\operatorname{TGF} \beta$, as previously reported $(29,39)$. extensive surface ulceration may be re-epithelialized; Feil et al. (49) have demonstrated that fully $80 \%$ of the colonic surface area denuded by instillation of acetic acid will be recovered by the migration of epithelium within $4 \mathrm{~h}$.

Previous studies from this laboratory have demonstrated the capability of a number of cytokines and growth factors to promote restitution using a simplified in vitro model $(29,39)$. These regulatory peptides which effect their actions through specific high-affinity cell surface receptors are produced by cellular constituents of the lamina propria especially in the context of cellular activation of inflammatory and immune response commonly seen after damage to the overlying epithelium (50). These factors may be reasonably presumed to promote gastrointestinal tract epithelial migration through the basolateral pole. The studies described in this report suggest that the important process of restitution may also be promoted through the combined action of trefoil peptides and mucin glycoproteins. This complex would appear complementary to the previously identified mechanisms insofar as it is localized exclusively to the apical surface. The fundamental distinction between the restitution promoting effects of the trefoil peptide containing complex and mucosal cytokines and growth factors is underscored by the lack of dependence of the former on modulation of TGF $\beta$ as an intermediate effector peptide.

These observations provide new insights into the dimensions of mucosal function. It appears that a complex of trefoil peptide and mucin glycoprotein produced by goblet cells both provides a continuous physical interface with the lumen and promotes rapid reestablishment of that continuity after injury. It is possible that this activity is directly related to the ability of trefoil peptides to promote formation of a surface viscoelastic gel by physical interaction with mucin glycoproteins. Preliminary studies have demonstrated that HSP, PSP, and ITF specifically enhance viscosity in mixtures with mucin glycoproteins ( $\mathrm{K}$. Lynch-Devaney and D. K. Podolsky, unpublished observation ). Although the studies described in this report demonstrate the functional effect of trefoil peptides in promoting restitution 


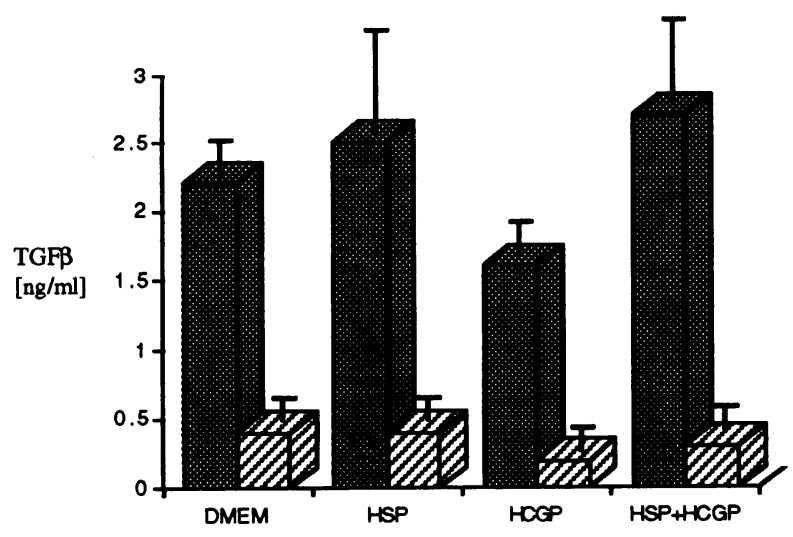

Figure 7. Effects of HSP an HCGP on production of bioactive TGF $\beta$ by wounded IEC- 6 monolayers. After treatment of wounded monolayers with HSP and/or HCGP, media and cells were harvested and the level of active and latent (defined as the total amount of bioactive $\operatorname{TGF} \beta$ present after acidification less that present in the absence of acidfication) was determined by the ability to inhibit proliferation of the Mv1Lu cell line and quantitated against a standard curve established with reagent TGFb. ( $\square)$ latent; ( $\square)$ bioactive.

through a TGF $\beta$-independent pathway, the mechanistic basis of this activity will be the focus of further studies.

Finally, the present study provides a new perspective on the functional role of trefoil peptides as a class. Despite an initial report of modest growth promoting effects of PSP when added to the media of some colon cancer-derived cell lines (18), we were unable to identify within the experimental conditions used in these studies any consistent stimulatory or inhibitory effect of any of the three trefoil peptides studied in a variety of cell lines. While it is possible that the lack of effect of the trefoil peptides could reflect the absence of suitable receptors, it is notable that one of these lines was responsive to the restitutionpromoting effects of these factors. Nonetheless, it is possible that trefoil factors could act as typical peptide growth factors in suitable target cells via receptors which are not involved in the pathway through which cell migration and restitution are mediated. In this context, it will be important to distinguish putative receptors from cell surface binding sites which might serve to anchor trefoil factors to the mucosal surface, perhaps complexed with mucin glycoproteins.

In addition, the present study suggests that trefoil peptides may share generic functional properties. Thus both HSP and ITF had comparable abilities to promote restitution of the IEC6 intestinal epithelial cell line although the former peptide is normally found in the proximal gastrointestinal tract. We presume that the gastric trefoil factor pS2 would have similar effects on restitution, and conversely all of these trefoil factors would promote restitution in gastric epithelium as well. Further, the ability of both human and rodent trefoil peptides to enhance migration of the rodent line underscores the conserved functional properties of this family of peptides in the gastrointestinal tract. We also anticipate that the rodent trefoil peptide (or other mammalian and perhaps amphibian trefoil peptides) could similarly stimulate restitution in non-transformed human gastrointestinal epithelium.

In parallel, these studies indicate that the trefoil peptides possess a common structural basis for functional interaction with mucin glycoproteins broadly. Thus mucin glycoproteins from either rat or man appeared to function in a cooperative fashion with the rodent and human trefoil peptides. Similarly, mucin glycoproteins isolated from two different sites of the rat gastrointestinal tract functioned in an essentially comparable manner in their interaction with trefoil peptides to enhance restitution in the in vitro model.

Although these studies have highlighted the interchangeable function of the trefoil peptides and mucin glycoproteins in the assays employed, insofar as the individual members of this family appear to have been evolutionarily conserved in a regionspecific manner, it is also reasonable to assume that each peptide possesses properties which may be specifically adapted to the sites of normal expression. These specific properties may include more exquisite specific interaction with site-specific mucin glycoproteins than could be resolved in the present model. Alternatively, these more specific features of the individual trefoil peptides and mucin glycoproteins could play a key role in functional properties of these substances in addition to their effects on restitution. While these studies have demonstrated the ability of trefoil peptides to promote restitution, it is possible that they also serve in other ways to protect the gastrointestinal tract mucosal integrity from damage.

\section{Acknowledgments}

This work was supported by grants from the National Institutes of Health (DK-34422 and DK-43351).

\section{References}

1. Thim, L. 1988. A surprising sequence homology. B. J. Letters. 253:309.

2. Carr, M. D. 1992. H NMR-based determination of the secondary structure of porcine pancreatic spasmolytic polypeptide: One of a new family of "trefoil" motif containing cell growth factors. Biochemistry. 31:1998-2004.

3. Hoffmann, W., and F. Hauser. 1993. The P-domain/trefoil motif: a role in renewal and pathology of mucous epithelia? Trends Biochem. Sci. 18:239-243.

4. Thim, L. 1989. A new family of growth factor-like peptides. "Trefoil", disulphide loop structures as a common feature in breast cancer associated peptide (pS2), pancreatic spasmolytic polypeptide (PSP), and frog skin peptides (spasmolysins). FEBS (Fed. Eur. Biochem. Soc.) Lett. 250:85-90.

5. Tomasetto, C., M.-C. Rio, C. Gautier, C. Wolf, M. Hareuveni, P. Chambon, and R. Lathe. 1990. hSP, the domain-duplicated homolog of pS2 protein, is coexpressed with pS2 in stomach but not in breast carcinoma. EMBO (Eur. Mol. Biol. Organ.) J. 9:407-414.

6. Hauser, F., and W. Hoffmann. 1992. P-domains as shuffled cysteine-rich modules in integumentary mucin C.1 (FIM-C.1) from Xenopus laevis. J. Biol. Chem. 267:24620-24624.

7. Rio, M. C., J. P. Bellocq, J. Y. Daniel, C. Tomasetto, R. Lathe, M. P. Chenard, A. Batzenschlager, and P. Chambon. 1988. Breast cancer-associated pS2 protein: Synthesis and secretion by normal stomach mucosa. Science (Wash. DC) 241:705-708.

8. Brown, A. M. C., J.-M. Jeltsch, M. Roberts, and P. Chambon. 1984. Activation of $\mathrm{pS} 2$ gene transcription is a primary response to estrogen in the human breast cancer cell line MCF-7. Proc. Natl. Acad. Sci. USA. 81:6344-6348.

9. Podolsky, D. K., K. Lynch-Devaney, J. Stow, P. Oates, B. Murgue, M. DeBeaumont, B. Sands, and Y. Mahida. 1993. Identification of human intestinal trefoil factor: goblet cell specific expression of a peptide targeted for apical secretion. J. Biol. Chem. 268:6694-6702.

10. Suemori, S., K. Lynch-Devaney, and D. K. Podolsky. 1991. Identification and characterization of rat intestinal trefoil factor: tissue- and cell-specific member of the trefoil protein family. Proc. Natl. Acad. Sci. USA. 88:11017-11021.

11. Hauser, F., E.-M. Gertzen, and W. Hoffmann. 1990. Expression of spasmolysin (FIM-A.1): An integumentary mucin from Xenopus laevis. Exp. Cell Res. 189:157-162.

12. Hauser, F., C. Roeben, and W. Hoffmann. 1992. xP2, a new member of the P-domain peptide family of potential growth factors, is synthesized in Xenopus laevis skin. J. Biol. Chem. 267:14451-14455.

13. Hauser, F., and W. Hoffman. 1991. XP1 and XP4. P-domain peptides expressed in Xenopus laevis stomach mucosa. J. Biol. Chem. 266:21306-21309.

14. Hoffmann, W. 1988. A new repetitive protein from Xenopus laevis skin 
highly homologous to pancreatic spasmolytic polypeptide. J. Biol. Chem. 263:7686-7690.

15. Rio, M.-C., M.-P. Chenard, C. Wolf, L. Marcellin, C. Tomasetto, R. Lathe, J.-P. Bellocq, and P. Chambon. 1991. Induction of pS2 and hSP genes as markers of mucosal ulceration of the digestive tract. Gastroenterology. 100:375-379.

16. Wright, N. A., R. Poulsom, G. Stamp, S. Van Noorden, C. Sarraf, G. Elia, D. Ahnen, R. Jeffery, J. Longcroft, C. Pike, M.-C. Rio, and P. Chambon. 1993. Trefoil peptide gene expression in gastrointestinal epithelial cells in inflammatory bowel disease. Gastroenterology. 104:12-20.

17. Wright, N. A., C. Pike, and G. Elia. 1990. Induction of a novel epidermal growth factor-secreting cell lineage by mucosal ulceration in human gastrointestinal stem cells. Nature (Lond.). 343:82-85.

18. Hoosein, N. M., L. Thim, K. H. Jørgensen, and M. G. Brattain. 1989. Growth stimulatory effect of pancreatic spasmolytic polypeptide on cultured colon and breast tumor cells. FEBS (Fed. Eur. Biochem. Soc.) Lett. 247:303-306.

19. Jørgensen, K. D., B. Diamant, K. H. Jørgensen, and L. Thim. 1982. Pancreatic Spasmolytic polypeptide (PSP): III. Pharmacology of a new porcine pancreatic polypeptide with spasmolytic and gastric acid secretion inhibitory effects. Reg. Pep. 3:231-243.

20. Thim, L., K. H. Jørgensen, and K. D. Jørgensen. 1982. Pancreatic Spasmolytic Polypeptide (PSP): II. Radioimmunological determination of PSP in porcine tissues, plasma and pancreatic juice. Reg. Pep. 3:221-230.

21. Jorgensen, K. H., L. Thim, and H. E. Jacobsen. 1982. Pancreatic spasmolytic polypeptide (PSP): I. Preparation and initial chemical characterization of a new polypeptide from porcine pancreas. Reg. Pep. 3:207-219.

22. Thim, L., K. Norris, F. Norris, P. F. Nielsen, S. E. Bjørn, M. Christensen, and J. Petersen. 1993. Purification and characterization of the trefoil peptide human spasmolytic polypeptide (hSP) produced in yeast. FEBS (Fed. Eur. Biochem. Soc.) Lett. 318:345-352.

23. Podolsky, D. K., and K. Isselbacher. 1983. Composition of human colonic mucin. Selective alteration in inflammatory bowel disease. J. Clin. Invest. 72:142153.

24. Podolsky, D. K. 1985. Oligosaccharide structures of human colonic mucin. J. Biol. Chem. 260:8262-8271.

25. Lamont, J. T., and A. S. Ventola. 1980. Purification and composition of colonic epithelial mucin. Biochim. Biophys. Acta. 626:234-243.

26. Massague, J. 1990. The transforming growth factor $\beta$ family. Annu. Rev. Cell Biol. 6:597-641.

27. Roberts, A. B., and M. B. Sporn. 1990. The transforming growth factor betas. In Handbook of experimental Pharmacology. Volume 95. M. B. Sporn, and A. B. Roberts, editors. Springer Verlag, Heidelberg. 419-472.

28. Quaroni, A., J. Wands, T. L. Trelstad, and K. J. Isselbacher. 1979. Epithelial cell cultures from rat small intestine. J. Cell Biol. 80:245-265.

29. Ciacci, C., S. E. Lind, and D. K. Podolsky. 1993. Transforming growth factor $\beta$ regulation of migration in wounded rat intestinal epithelial monolayers. Gastroenterology. 105:93-101.

30. McCormack, S. A., M. J. Viar, and L. R. Johnson. 1992. Migration of IEC-6 cells: a model for mucosal healing. Am. J. Physiol. 263G:426-435.

31. Sato, Y., and D. P. Rifkin. 1989. Inhibition of endothelial cell movement by pericytes and smooth muscle cells: activation of latent transforming growth factor $\beta_{1}$ like molecules by plasmin during coculture. J. Cell Biol. 109:309-315.

32. Danielpour, D., L. L. Dart, K. C. Flanders, A. B. Roberts, and M. B. Sporn. 1989. Immunodetection and quantitation of the two forms of transforming growth factor $\beta$ (TGF- $\beta_{1}$ and TGF- $\beta_{2}$ ) secreted by cells in culture. J. Cell. Physiol. 138:79-86.

33. Neutra, M., and D. Louvard. 1989. Differentiation of intestinal cells in vitro. In Functional Epithelial Cells in Culture. Alan R. Liss, Inc. 363-398.

34. Chinery, R., R. Poulsom, G. Elia, A. M. Hanby, and N. A. Wright. 1993. Expression and purification of a trefoil peptide motif in a $\beta$-galactosidase fusion protein and its use to search for trefoil-binding sites. Eur. J. Biochem. 212:557563.

35. Frandsen, E. K., K. H. Jørgensen, and L. Thim. 1986. Receptor binding of pancreatic spasmolytic polypeptide (PSP) in rat intestinal mucosal cell membranes inhibits the adenylate cyclase activity. Reg. Pep. 16:291-297.

36. Kurokawa, M., K. Lynch, and D. K. Podolsky. 1987. Effects of growth factors on an intestinal epithelial cell line; transforming growth factor $\beta$ inhibits proliferation and stimulates differentiation. Biochem. Biophys. Res. Commun. 142:775-782.

37. Basson, M. D., I. M. Modlin, and J. A. Madri. 1992. Human enterocyte (Caco-2) migration is modulated in vitro by extra-cellular matrix composition and epidermal growth factor. J. Clin. Invest. 90:15-23.

38. Basson, M. D., J. M. Modlin, S. D. Flynn, B. P. Jena, and J. A. Madri. 1992. Independent modulation of enterocyte migration and proliferation by growth factors, matrix proteins, and pharmacologic agents in an in vitro model of mucosal healing. Surgery. 112:299-308.

39. Dignass, A., and D. K. Podolsky. 1993. Cytokine modulation of intestinal epithelial cell restitution: Central role of Transforming Growth Factor $\beta$. Gastroenterology. 105:1323-1332.

40. Blay, J., and K. D. Brown. 1985. Epidermal growth factor promotes the chemotactic migration of cultured rat intestinal epithelial cells. J. Cell. Physiol. 24:107-112.

41. Pircher, R., P. Jullien, and D. A. Lawrence. 1986. Beta ${ }^{\circ}$ transforming growth factor is stored in human blood platelets as a latent high molecular weight complex. Biochem. Biophys. Res. Commun. 136:30-37.

42. Madara, J. L., and J. Stafford. 1989. Interferon-gamma directly affects barrier function of cultured intestinal epithelial monolayers. J. Clin. Invest. 83:724-727.

43. Moore, R., S. Carison, and J. L. Madara. 1989. Rapid barrier restitution in an in vitro model of intestinal epithelial injury. Lab. Invest. 60:237-244.

44. Lacy, E. R. 1988. Epithelial restitution in the gastrointestinal tract. J. Clin. Gastroenterol. 10:72-77.

45. Nusrat, A., C. Delp, and J. Madara. 1992. Intestinal epithelial restitution. J. Clin. Invest. 89:1501-1511.

46. Rutten, M. J., and S. Ito. 1993. Morphology and electrophysiology of guinea pig gastric mucosal repair in vitro. Am. J. Physiol. 244G:171-182.

47. Silen, W. 1987. Gastric mucosal defense and repair. In Physiology of the Gastrointestinal Tract, 2nd edition. L. R. Johnson, editor. Raven Press, New York. 1044-1069.

48. Waller, D. A., N. W. Thomas, and T. J. Self. 1988. Epithelial restitution in the large intestine of the rat following insult with bile salts. Virchows Arch. A. Pathol. Anat. 414:77-81.

49. Feil, W., E. Wentzl, P. Vattay, M. Starlinger, R. Sogukoglu, and R. Schiessel. 1987. Repair of rabbit duodenal mucosa after acid injury in vivo and in vitro. Gastroenterology. 92:1973-1986.

50. Nathan, C., and M. Sporn. 1991. Cytokines in context. J. Cell Biol. 113:981-986 